\title{
PERSPECTIVAS DE DESENVOLVIMENTO REGIONAL COM A EXPLORAÇÃO DAS RESERVAS DE FERRO NO MUNICÍPIO DE CAETITÉ, BAHIA
}

Outlook regional development with the operation of iron in reserves caetité county, Bahia

Bethania M. S. Pontes ${ }^{1}$, Suely M. B. Silva ${ }^{1}$, Márcio L. S. C.Barros², Felisbela M. C. Oliveira ${ }^{3}$ e Mikaelly E. M. C. Rocha ${ }^{1}$

${ }^{1}$ Mestre, Programa de Pós-Graduação em Engenharia Mineral, Universidade Federal de Pernambuco, Recife, Brasil.

${ }^{2}$ Doutor, Engenharia de Minas, Universidade Federal de Pernambuco, Recife, Brasil.

${ }^{3}$ Doutor, Geologia, Universidade Federal de Pernambuco, Recife, Brasil.

\section{Resumo}

O Brasil é, mundialmente, considerado como um produtor em potencial do minério de ferro. Dos depósitos conhecidos e explorados os estados de Minas Gerais, Pará e Mato Grosso do Sul detêm aproximadamente 99\% das reservas. Nos últimos anos a crescente demanda, pelo mineral, levou pesquisadores a novas jazidas no município de Caetité, mesorregião centro-sul da Bahia. A implantação de projetos para a exploração e a logística para o escoamento do produto, vão gerar tributos e movimentar a economia local e regional, elevando o estado ao terceiro maior produtor do minério no país. Da região interiorana até o litoral, mudanças nos aspectos paisagísticos, ambientais e socioeconômicos começam a fazer parte do cenário baiano, devido à inserção do distrito ferrífero.

Palavras-chave: Mineração, ferro, Bahia, Caetité,

\section{Abstract}

Brazil is globally regarded as a potential producer of iron ore. Deposits known and explored the states of Minas Gerais, Pará and Mato Grosso do Sul hold approximately 99\% of the reserves. In recent years the increasing demand for mineral deposits led to new researchers in the municipality of Caetité, south-central region of Bahia. The project implementation for the operation and logistics for the marketing of the product will generate taxes and moving the local and regional economy, bringing the state to the third largest producer of iron ore in the country. The hinterland to the coast, changes in landscape aspects, environmental and socioeconomic become part of the scenery Bahia, due to the insertion of the district ferriferous.

Keywords: Mining, iron, Bahia, Caetité. 


\section{Introdução}

A mineração é um dos setores básicos na economia de um país e a atividade essencial para a produção de bens, sendo responsável por fornecer matéria-prima para os demais setores produtivos. O Brasil possui em seu vasto território uma grande diversidade de terrenos $\mathrm{e}$ formações geológicas, conferindo um enorme potencial para a indústria extrativa mineira.

O ferro é o quarto elemento formador de rocha mais abundante e compõe cerca de $5 \%$ da crosta da Terra. O Brasil ocupa terceira posição em produção e reservas do minério, e junto com a Austrália dominam as exportações mundiais do ferro, com cerca de um terço do total das exportações (USGS, 2014). Estima-se que $98 \%$ do minério embarcado no mundo é consumida na produção de ferro e aço. E o restante (2\%) é utilizado na fabricação de cimento, pigmentos, lastro, produtos agrícolas ou produtos químicos especiais (DNPM, 2013).

Na Bahia, de acordo com a Secretaria de Estado de Planejamento e Desenvolvimento Econômico (SEPLAN), pesquisas e mapeamentos geológicos constataram que a região de Caetité possui uma das maiores reservas de minério de ferro do país, sendo capaz de inserir o estado definitivamente entre os principais produtores, a exemplo de Minas Gerais e Pará. O potencial da jazida é de quatro a seis bilhões de toneladas do minério bruto em $360 \mathrm{~km}$ de extensão, numa área que vai da divisa da Bahia com Minas Gerais até o município de Xique-Xique, já devidamente identificados pela Companhia de Pesquisa e Recursos Minerais (CPRM) e pela Companhia Baiana de Pesquisa Mineral (CBPM) (SEPLAN ${ }^{1 ; 2}, 2006$ ).

Com a descoberta do depósito, em Caetité, o estado da Bahia tem atraído investimentos para implantar projetos visando a exploração e escoamento do minério de ferro. Desse modo contribuindo para mudanças no cenário do interior ao litoral e promovendo uma maior integração no Estado com desenvolvimento socioeconômico local e regional.

\section{A importância do minério de ferro para o Brasil}

O ferro é um metal abundante na Terra e elemento indispensável para a civilização moderna. Como matéria prima de excelência para o aço é fundamental principalmente aos setores de bens de consumo e de infraestrutura (STEINWEG \& SCHUIT, 2014).

$\mathrm{O}$ aumento da demanda mundial pelo minério de ferro, principalmente em países com elevados índices de crescimento econômico como a China, impulsionou a produção do mineral no Brasil. Nos últimos anos o setor mineral no país tem registrado crescimento econômico e mudanças significativas na infraestrutura, bem como nos aspectos socioeconômico da população.

Das reservas mundiais de minério bruto o Brasil desponta em segundo lugar com 31 bilhões de toneladas 
(USGS, 2015). Os maiores estados brasileiros produtores de minérios, no primeiro semestre de 2014, de acordo com o recolhimento de Compensação Financeira pela Exploração de Recursos Minerais (CFEM) foram Minas Gerais $(48,2 \%)$ e Pará $(31,3 \%)$, os grandes produtores do ferro, concentraram $79,5 \%$ da arrecadação dos royalties da mineração. A produção em 2014.1 apresentou um aumento de 14,5\% em comparação ao mesmo período de 2013 (DNPM, 2014).

No que se refere às exportações da indústria extrativa mineral consta uma diminuição da participação do minério de ferro de 80,2\% em 2013 para $77,7 \%$ no mesmo período em 2014 (Figura 1). Na análise da evolução do comércio exterior evidenciou-se uma piora nas contas externas, devido à queda nas exportações do minério de ferro. Constata-se que o fator causador da retração foi a queda do preço médio das exportações desse minério (DNPM, 2014).

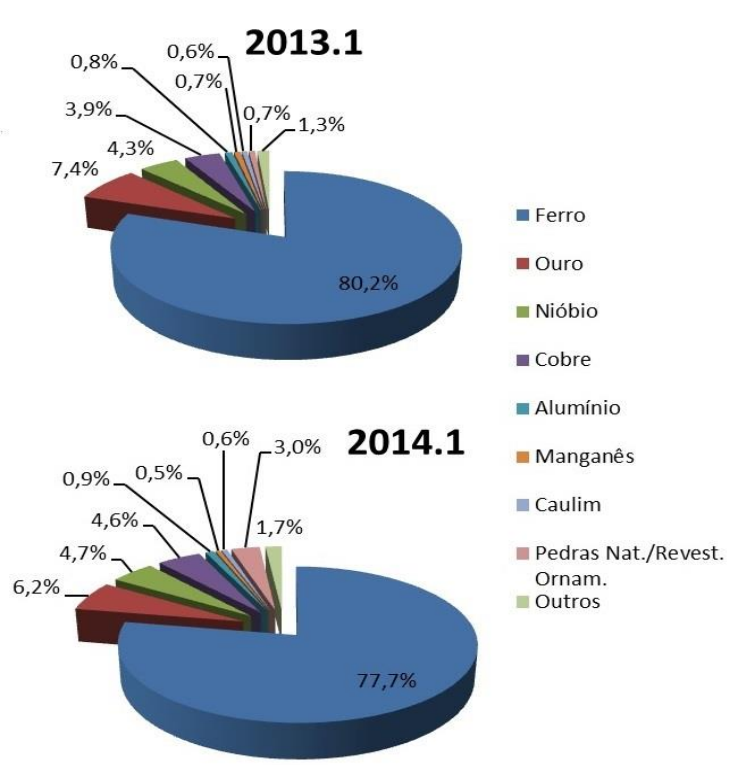

Figura 1 - Distribuição das exportações por produto. Fonte: DNPM, 2014
Durante décadas o valor do minério de ferro permaneceu relativamente estável, mas uma combinação de fatores, incluindo a crise financeira global fez o preço cair a partir de 2011. Apesar do cenário mundial ter mostrado uma queda na demanda por commodities minerais, especialmente por parte da China (WORLD BANK, 2014) os investimentos na extração e produção brasileira do mineral ainda persistem.

Dentre os estados do Brasil a receber investimentos entre 2011 a 2015 no setor mineral, a Bahia destaca-se em 3o lugar (Figura 2), atrás de Minas Gerais e Pará, respectivamente. A riqueza de recursos minerais no território baiano tem sido fator decisivo para o desenvolvimento econômico do estado. De acordo com o Governo da Bahia (2008) o setor mineral, principalmente no que concerne aos metais básicos e preciosos, e aos projetos de vanádio, níquel, ferro, ouro e diamante, retratam com propriedade os investimentos nesse setor. No plano da mineração os projetos voltados para o aproveitamento das jazidas tendem a impulsionar o estado a ocupar a terceira maior jurisdição brasileira de mineração.

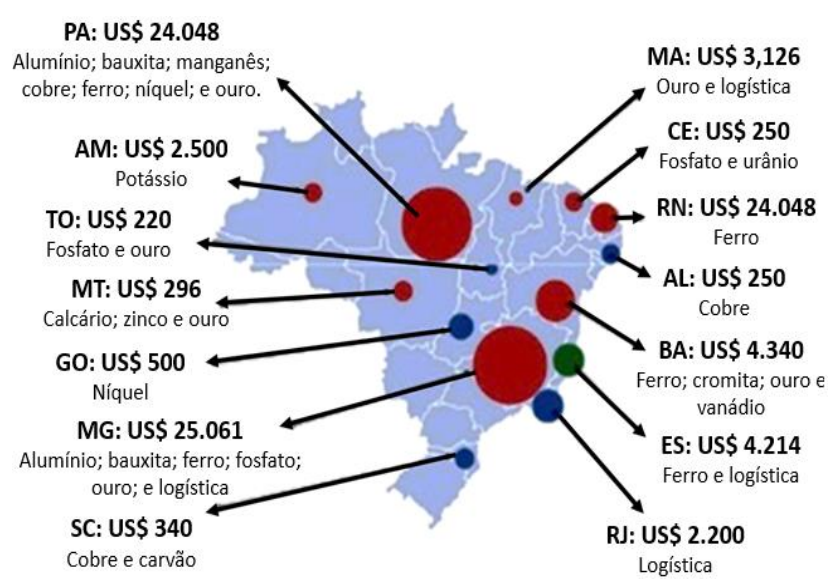

Figura 2 - Principais investimentos na mineração (2011 a 2015). Fonte: DNPM, 2011. 


\section{Cenário na Bahia com a descoberta do depósito de ferro em Caetité}

A Bahia é um dos estados brasileiros que tem recebido destaque na produção mineral. Este setor representa uma das atividades que contribui de forma significativa para o desenvolvimento socioeconômico em várias regiões. $\mathrm{O}$ setor de mineração do país investirá no estado cerca de US\$ 6,7 bilhões até o ano 2015 , isso implica em aproximadamente $10 \%$ do total dos recursos previstos pelo setor para todo o país (US\$ 68,5 bilhões) no período, além de recursos privados que também serão aplicados (ADIMB ${ }^{2}$, 2012).

A dinâmica mineral na Bahia vem apontando para mudanças em função de projetos de caráter estruturante que vêm sendo implantados no estado, e dentre eles o da produção de minério de ferro em Caetité (BAHIA ${ }^{2}$, 2011). E esse processo de mudanças tende a se intensificar à medida em que seu potencial de recursos minerais é melhor conhecido.

O município de Caetité localiza-se no sertão produtivo da Bahia (Figura 3), que se insere na região econômica da Serra Geral cuja área apresenta potencial geológico para ocorrência de minerais (IBGE, 2010). A abundância dos recursos naturais se configura como importante fator ao desenvolvimento regional, e a principal atividade geradora de mão de obra da região. Dentre os minerais recebem destaque o ferro, a ametista, o granito, o manganês, a argila, os cristais, e o urânio. Com exceção do urânio, todos os outros são explorados por empresas privadas (SILVA, 2007).
Pesquisas concluíram pela existência de extensa jazida ferrífera em Caetité e adjacências, cujo potencial já era esperado há algumas décadas. $\mathrm{O}$ município já desponta como polo regional produtor de recursos minerais. E com essa descoberta o potencial da região será elevado, trazendo expressivas modificações na matriz mineral do estado.

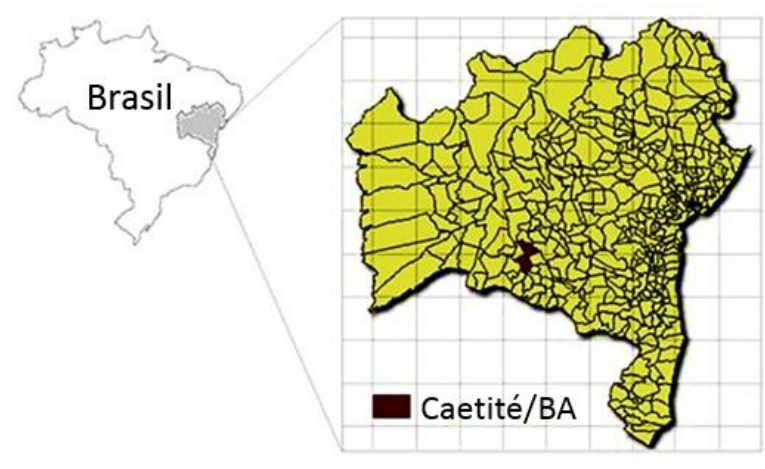

Figura 3 - Localização de Caetité/BA Fonte: SEI, 2012. Adapt.

A exploração do minério de ferro em Caetité cria perspectivas de mudanças nos aspectos paisagísticos, bem como de trazer desenvolvimento socioeconômico local e regional (MME, 2009), pois a reserva atraiu investidores a fim de implantar projetos para a extração do mineral (IBGE, 2010). A atividade tem a previsão de explorar 450 a 750 milhões de toneladas do produto. Estima-se que $10 \%$ dos investimentos previstos para o setor de mineração no país sejam destinados a Bahia até o ano de 2015, isso implica em aproximadamente US\$ 6,7 bilhões dos US\$ 68,5 bilhões, além dos investimentos privados (BAMIN, 2010).

A mineração do ferro representa a mais importante atividade mineral do 
país pelos recursos financeiros envolvidos. Desde a extração mineral até a comercialização do produto passa-se pela mão de obra; arrecadação de impostos e da CFEM; e a logística de transporte (rodoviário, ferroviário e marítimo), além de desenvolver as comunidades, favorece o desenvolvimento de outras atividades ao longo das vias de escoamento do minério. Foi assim com o "Quadrilátero Ferrífero", em Minas Gerais que atraiu as siderúrgicas que constituem o "Vale do Aço", como também no distrito mineiro de "Carajás" que além de atrair a produção siderúrgica para o entorno do seu caminho para o mar, criou nas periferias dos portos de embarque outras atividades de aproveitamento (pelotização) e transformação mineral, siderurgia (MME, 2009).

A base mineral da Bahia aponta para mudanças em função da implantação de grandes empreendimentos. Certamente o desenvolvimento de um depósito mineral, como o de ferro no município de Caetité, pode ser uma "oportunidade" de melhoria socioeconômica para a região (Figura 4).

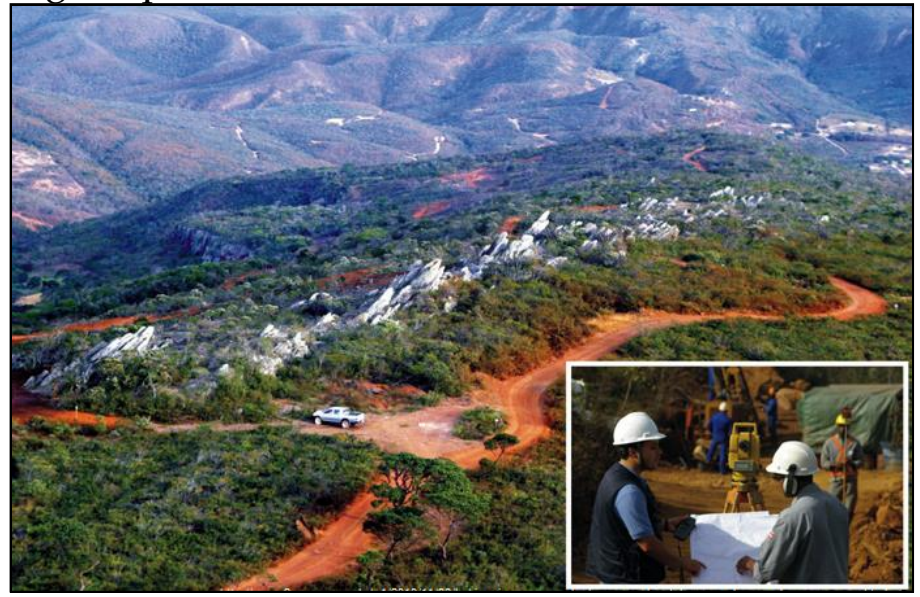

Figura 4 - Afloramento do minério de ferro em Caetité/BA. Fonte: BAMIN, 2010

O minério de ferro de Caetité é considerado de baixo teor, cuja concentração é de 35 a 40\%. Para atingir a concentração exigida pelo mercado $(66 \%$ a $68 \%$ Fe), necessita de beneficiamento (IBRAM, 2010). E para tal o empreendimento envolve a extração e o beneficiamento numa estrutura onde estará instalado o complexo (figura 5). A mina terá a capacidade de produzir cerca de 18 milhões de toneladas do minério de ferro por ano, contribuindo para que a Bahia passe da quinta para a terceira posição no ranking de produção do mineral, no país (IBRAM, 2010).

No processo de mudanças do cenário baiano também consta a logística de transporte e de infraestrutura para escoamento do produto. $\mathrm{O}$ transporte envolve a construção de $430 \mathrm{~km}$ de uma rede ferroviária e de um terminal de embarque privativo, em Ponta da Tulha, Ilhéus (BAMIN¹, 2011). 


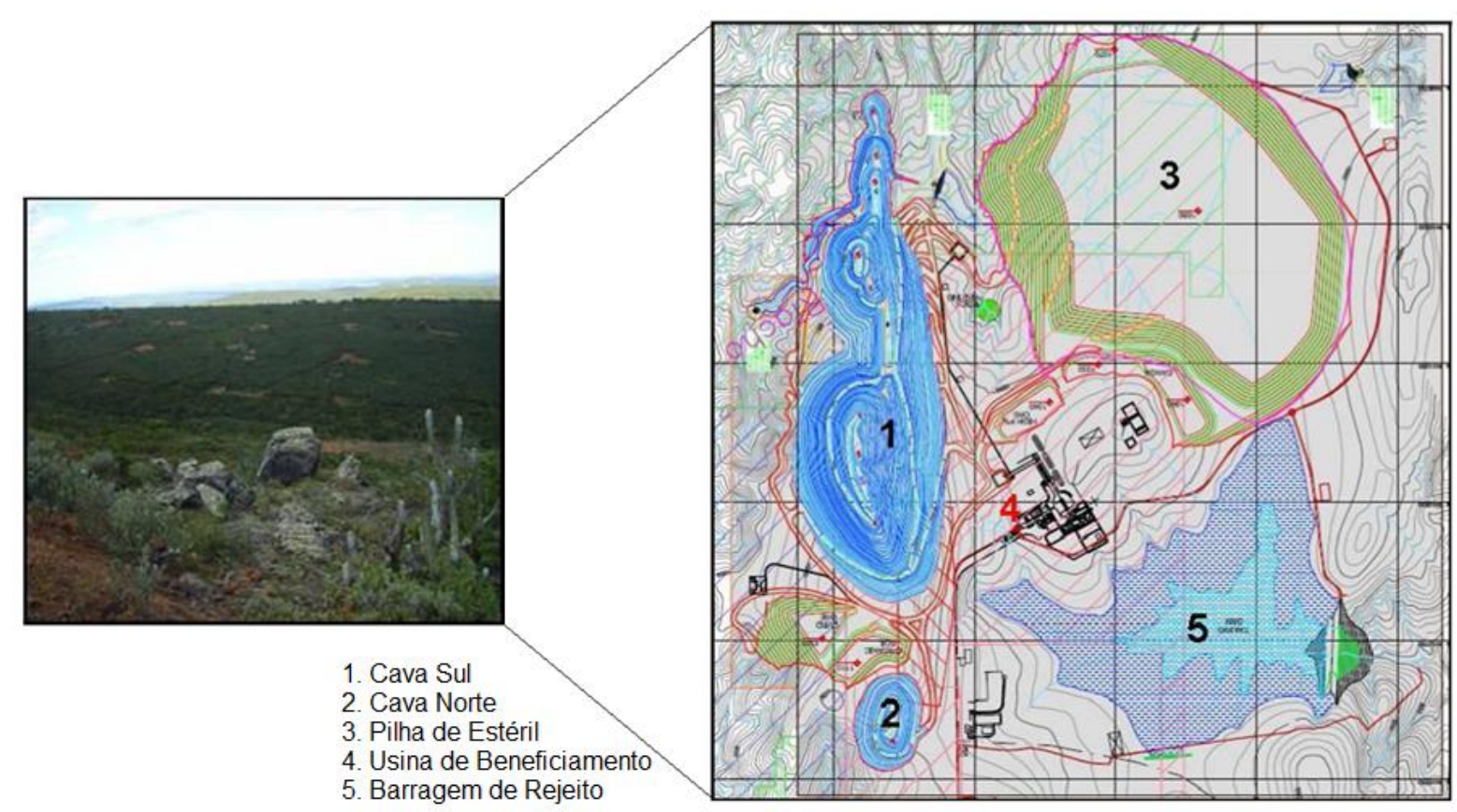

Figura 5 - Área de instalação do complexo para a extração e beneficiamento do minério de ferro. Fonte: BAMIN², 2011

A construção da ferrovia objetiva viabilizar o transporte do minério de ferro bem como o de outros produtos (insumos agrícolas, fertilizantes, biocombustíveis etc), produzidos no oeste, sudoeste e sul da Bahia. Neste sentido resgata-se o projeto da Ferrovia Oeste-Leste (FIOL), idealizada na década de 50, que interliga o estado desde o litoral até o extremo oeste, tendo como zona de influência 49 municípios da Bahia, e numa maior integração 15 municípios do Tocantins (figura 6), chegando futuramente até Campos Belos em Goiás (SEPLAN, 2010).

Com a FIOL a capacidade de movimentação inicial será em torno de 40 milhões de toneladas de produtos por ano, e o seu funcionamento reduz o custo no transporte rodoviário em aproximadamente $30 \%$, tornando o transporte regular e mais rápido, além de promover a dinamização da economia regional. Com essa logística o produto final é transportado pela ferrovia e chega até o terminal portuário, Porto Sul, de uso privativo que se pretende implantar em Ilhéus, na Ponta de Tulha, de onde a produção pode enfim ser exportada (Figura 7) (Bahia ${ }^{2}$, 2011).

A construção de um complexo portuário é um empreendimento defendido para viabilizar o embarque para a exportação do minério de ferro. A área para recebimento do minério de ferro contará com infraestrutura que abrigará as instalações e os demais serviços (IBRAM, 2010). Vale destacar que a implantação do empreendimento, para extração e destinação do minério, necessita para o pleno funcionamento de infraestrutura de transporte e de embarque para exportação do produto. 


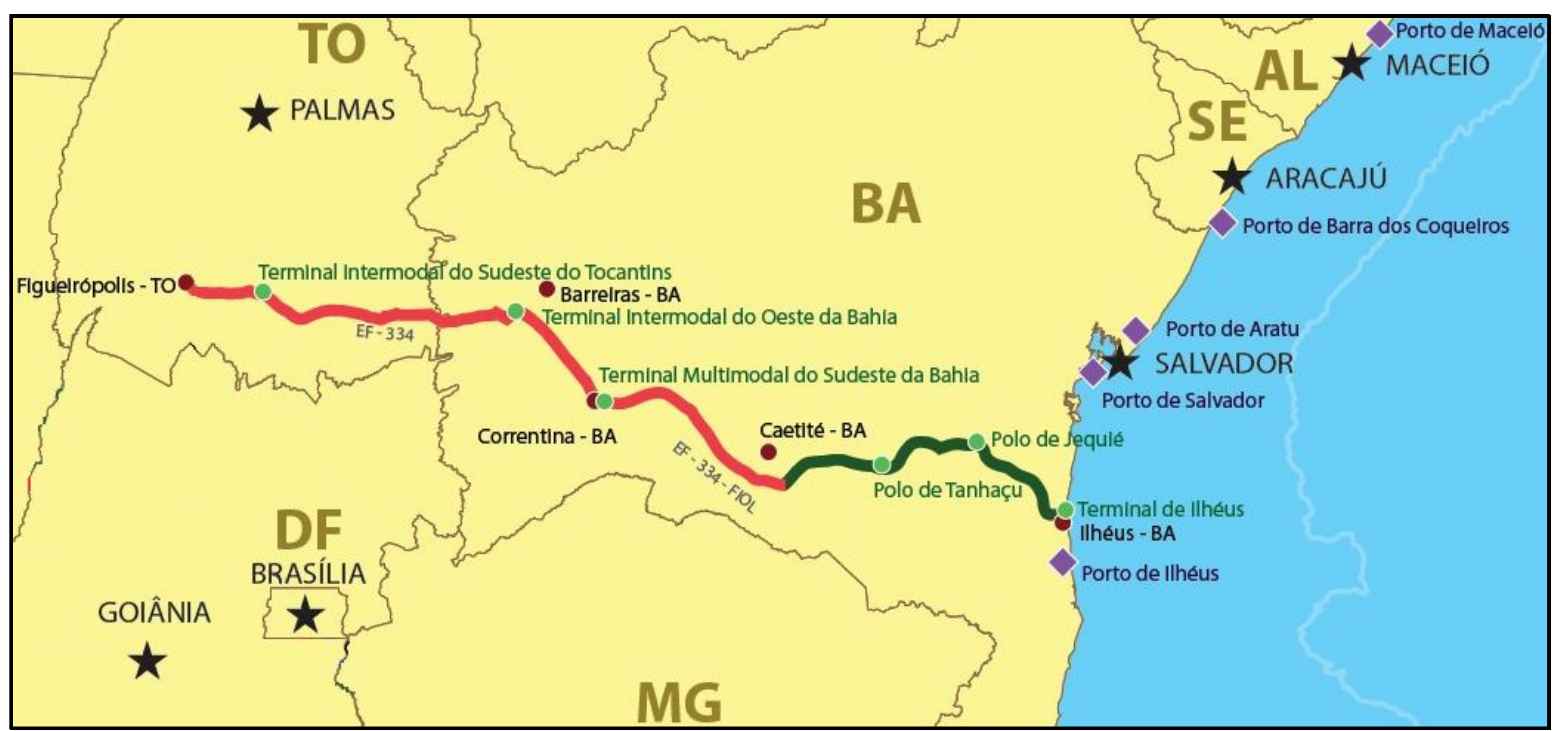

Figura 6 - Ferrovia de integração Oeste-Leste. Fonte: Base de dados da Valec, 2013

Um impacto significativo na Caetité, virá demanda por hotéis, economia baiana é esperado, pois todo o restaurantes, construção civil, linhas projeto engloba a instalação do aéreas, linhas de transmissão de energia, empreendimento em Caetité, a impostos, capacitação de mão de obra, construção da FIOL, do Porto Sul, e incluindo o ordenamento urbano de posteriormente de um aeroporto várias cidades nas regiões de internacional em Ilhéus. Ressalta-se que, abrangência dos empreendimentos em consequência da mineração em (DESENBAHIA, 2010).

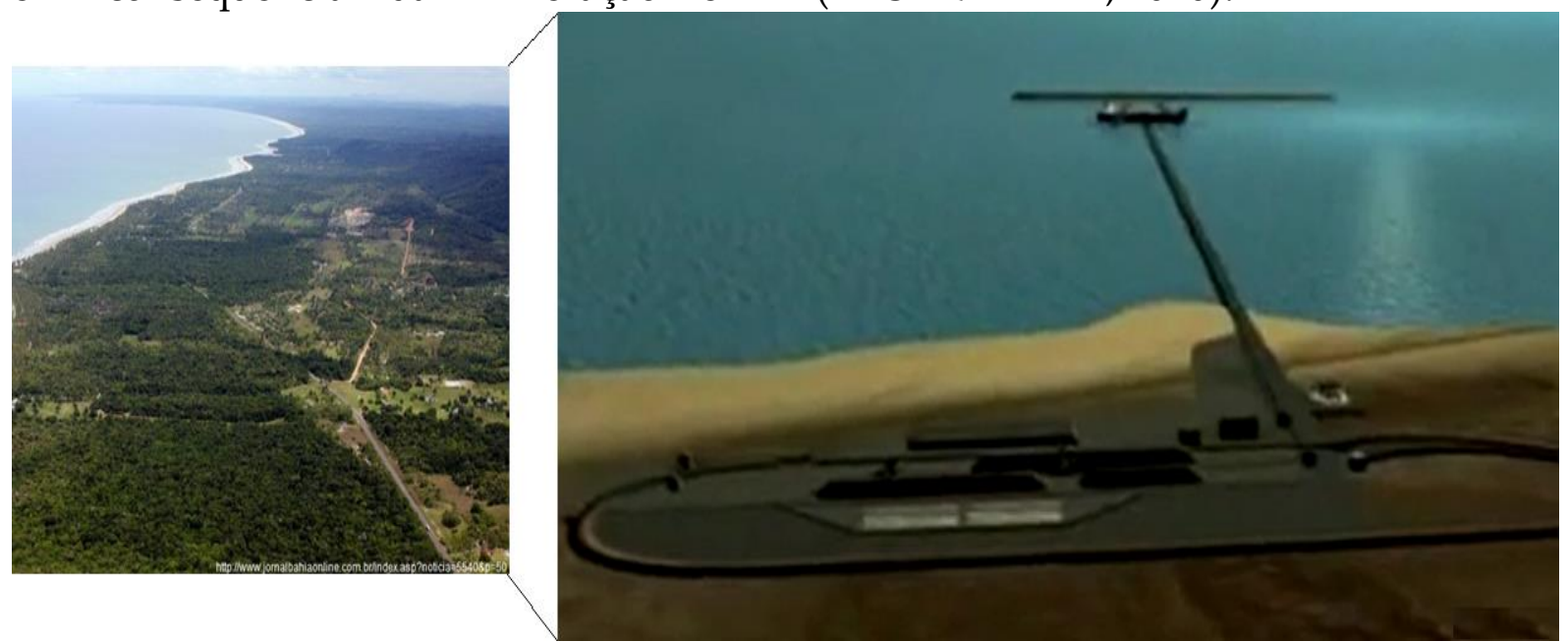

Figura 7 - Local de implantação do porto privativo em Ilhéus. Fonte: BAMIN², 2011.

O potencial e a tradição da Bahia na área de recursos minerais, somados às possibilidades de geração de emprego e renda do setor, justificam as atenções pelas iniciativas públicas e privadas do setor de mineração, como segmento impulsionador do crescimento e da interiorização do desenvolvimento (BAHIA 2008). As mudanças paisagísticas e socioeconômicas passam assim a fazer parte do cenário baiano. $\mathrm{O}$ eixo de crescimento será, em grande 
medida, ancorado no canal de escoamento formado pela FIOL (Figura 8) e o Porto Sul, que será viabilizado devido ao projeto da mineração em Caetité (BAHIA ${ }^{1}$, 2011). Entretanto todo grande empreendimento traz por um lado benefícios e por outro impactos aos ambientes naturais.

Quando se fala de mineração, não há como não fazer referência ao meio ambiente e aos riscos aos quais estão expostas as comunidades locais. Em geral, a mineração provoca um conjunto de efeitos não desejados como: alterações no ambiente; conflitos de uso do solo; depreciação de imóveis circunvizinhos; geração de áreas degradadas; e transtornos ao tráfego urbano, dentre outros (BITAR, 1997 apud FARIAS, 2002). Os entraves são fatores que contribuem para a lentidão nas obras. E para acelerar tais processos, o Governo da Bahia trabalha junto ao TCU, com vistas a auxiliar nas desapropriações, bem como discutir as entraves para a liberação das construções (ADIMB ${ }^{1}$, 2012).

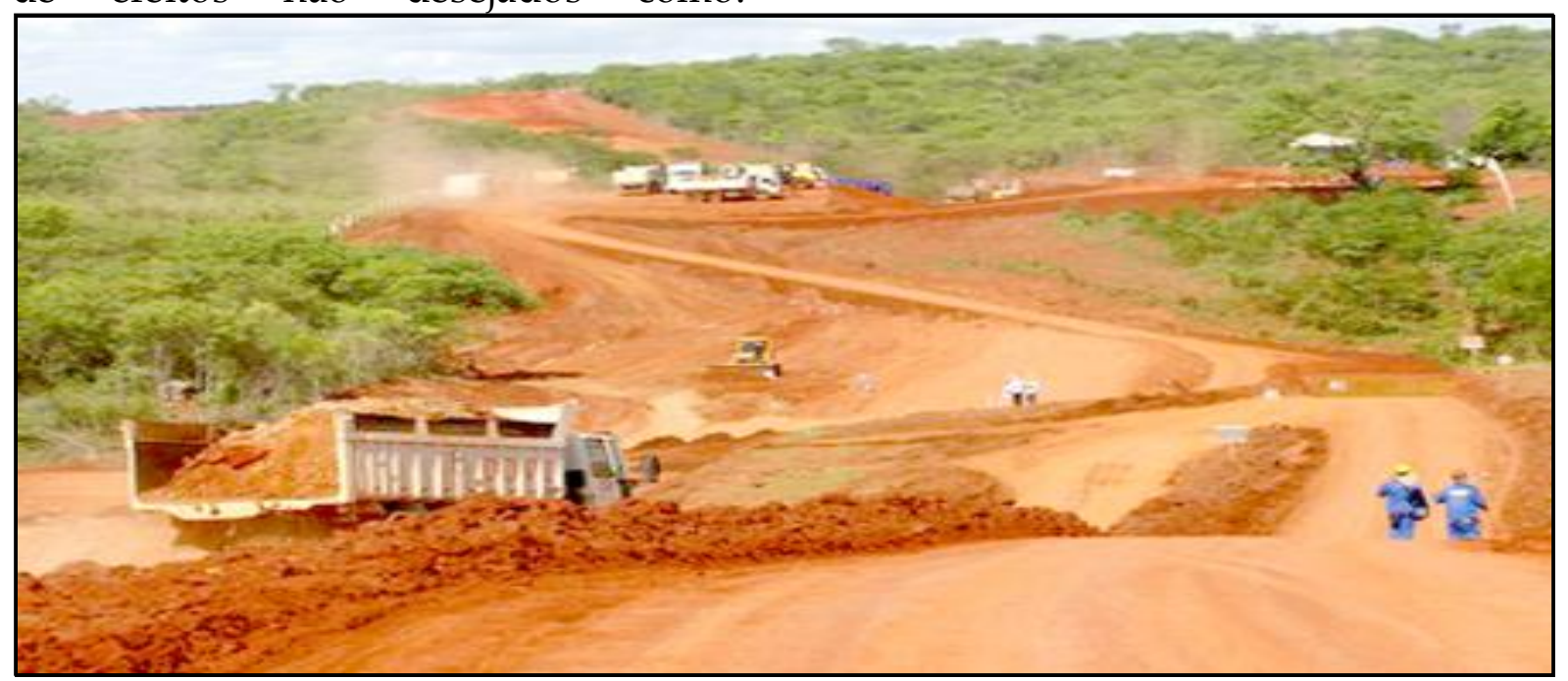

Figura 8 - Trecho em construção da FIOL. Fonte: BAMIN, 2010

4 A mineração de ferro em Caetité e a questão ambiental

A mineração é sem dúvida uma atividade de extrema importância para atender as necessidades, atualmente consideradas como básicas para a humanidade. Entretanto provoca uma série de efeitos indesejados e inevitáveis, tanto ao ambiente natural como aos aspectos culturais das comunidades locais.

Na mineração de ferro com estrutura semelhante ao projeto no município de Caetité cujo método de lavra é a de céu aberto com cava de extração, planta de beneficiamento, pilha de disposição de estéril, barragem de disposição de rejeitos, sistema de suprimento de água, e Estação de Tratamento de Efluentes (ETE), os impactos no ambiente natural são variados, recebendo destaque as alterações paisagísticas; os efeitos no sistema hídrico; a perda de fauna e flora; e a pressão demográfica. 
Os impactos ambientais decorrentes das alterações nas paisagens se dão devido às cavas e às pilhas de estéril. Como a extração é realizada através de explosões, o relevo vai se transformando em "grandes buracos" e o material descartado é depositado em pilhas, criando montanhas desses materiais. Já os impactos no sistema hídrico ocorrem porque há uma demanda enorme de água na fase do beneficiamento e há a necessidade de rebaixar o lençol freático e drenar as jazidas. Ou seja, a água que seria lentamente utilizada é rapidamente escoada. Sendo assim, há uma diminuição na capacidade hídrica da região (FAUSTINO \& FURTADO, 2013). Há também o volume de rochas que fica exposto aos processos de oxidação, podendo ocorrer a formação de drenagens ácidas com efeitos nefastos para a qualidade das águas, modificando o $\mathrm{pH}$, alterando assim o ambiente (flora e fauna) onde o líquido é drenado.

No processo de mineração também ocorre o desmatamento a fim de se implantar o complexo como um todo, especialmente nas lavras onde se requeira o uso da madeira para a produção de energia, havendo então a retirada vegetação nativa com perda de flora e fauna. É importante salientar que nas áreas onde há o processo de mineração ocorre aumento da população, em decorrência dos fluxos migratórios. E não menos importante essas áreas são apontadas em seus aspectos negativos pela produção de pó e ruídos gerados.

A construção da FIOL e do Porto Sul também fazem parte do empreendimento em Caetité, para fins transporte e embarque para a exportação do minério. Sendo assim um ponto do litoral baiano foi escolhido para a instalação de um porto interligado à jazida mineral, tendo a FIOL como via para o escoamento do produto. Os embates sobre os problemas no ambiente natural, no caso da FIOL, são em função das alterações no uso e ocupação do solo. Os impactos diretos são de poluição do ar, ruídos, vibrações, modificações na topografia e na drenagem superficial, e supressão da vegetação nativa, com perda de flora e fauna (OIKOS, 2009). Já no caso da construção do Porto Sul os impactos serão: alteração na qualidade das águas e do ar; assoreamento; vibração e ruídos; perda de cobertura vegetal e fauna; geração de resíduos sólidos; e etc. (HYDROS, 2012). E todo o impasse decorre do fato de Ilhéus ser uma área que abriga biodiversidade como remanescentes de Mata Atlântica, restingas, manguezais e recifes de coral, e ser o habitat de várias espécies.

$\mathrm{O}$ setor de mineração causa a degradação dos ambientes e ecossistemas naturais inevitavelmente, e não se pode desconsiderar a importância ecológica e dos riscos para a população local e regional. Os impactos exigem procedimentos que reconheçam e recompensem as perdas causadas com métodos mitigatórios, embora não se repare fielmente os recursos perdidos.

\section{Considerações finais}

O estado da Bahia diante do seu potencial em ocorrências minerais tem 
tido grande destaque nacional em investimentos no setor de mineração. No Brasil, o estado ocupa o 5ำ lugar na produção do minério ferro, mas a tendência é que suba no ranking para a $3^{\text {o }}$ posição com a descoberta do depósito de minério de ferro no município sertanejo de Caetité. A jazida traz uma estimativa de exploração do minério numa ordem aproximada de 450 a 750 milhões de toneladas. A demanda por infraestrutura para produção e escoamento do produto trará mudanças significativas no cenário baiano.

A implantação de projetos estruturadores passa a promover alterações nas paisagens e nos aspectos socioeconômicos, do sertão ao litoral da Bahia. As atividades humanas, em

\section{Referências}

ADIMB $^{1}$. Agência para o Desenvolvimento Tecnológico da Indústria Mineral Brasileira. Atraso nas obras da OesteLeste frusta planos da BAMIN. Valor Econômico. Brasília, 2012, 2p.

$\mathrm{ADIMB}^{2}$. Agência para o Desenvolvimento Tecnológico da Indústria Mineral Brasileira. Investimentos: Bahia recebe US\$ 6,7 bilhões até 2015. Brasil Mineral. Brasília, 2012, 6p.

BAHIA. Avaliação da Produção Mineral na Bahia 2002-2006. Governo do Estado da Bahia. Secretaria da Indústria, Comércio e Mineração. Salvador, 2008. 93 p.

BAHIA ${ }^{1}$. Caderno Especial de Mineração na Bahia. Projeto Especial Marketing: Jornal À Tarde. Salvador, 2011. 11p.

BAHIA². Núcleo Regional da Bahia. Política Industrial da Bahia: Estratégias e Proposições. Documento Síntese/ geral, causam impactos no modo de vida das pessoas e no meio ambiente. As modificações, principalmente, nos aspectos naturais têm ocasionado grandes impasses entre a população e os empreendedores ocasionando em atrasos na exploração e produção do minério de ferro.

A exploração do depósito mineral em Caetité traz a perspectiva do desenvolvimento regional, melhorias nas condições socioeconômicas, e alavancará o crescimento do Estado como um todo, embora a questão ambiental mereça enfoque importante considerando, os danos irreparáveis causados ao meio natural, notadamente ao Rio São Francisco e à porção de Mata Atlântica do Sul da Bahia.

Instituto Euvaldo Lodi. Projeto Aliança. Sistema FIEB. Salvador, 2011. 26p.

BAMIN, Bahia Mineração S.A. Press Releases. Release Institucional. ENRC adquire ações da Zamin e se torna a única quotista da Bahia Mineração. Salvador, 2010, 2p.

BAMIN1. Bahia Mineração S.A. Press Releases. Release Institucional. Bahia será o terceiro maior produtor de minério de ferro do país com o projeto da BAMIN. Salvador, 2011. 4p.

BAMIN². Bahia Mineração S.A. Relatório Técnico de Garantia Ambiental - RTGA. Salvador, 2011. 174p.

BITAR, O.Y. Avaliação da recuperação de áreas degradadas para mineração Região Metropolitana de São Paulo, 1997. In FARIAS, C.E.G. Mineração e meio ambiente no Brasil. Brasília: Centro de Gestão e Estudos Estratégicos Ciência, 
Tecnologia e Inovação (CGEE). Brasília, 2002. 40p.

DESENBAHIA, Agência de Fomento do Estado da Bahia. Bahia será terceiro produtor nacional de minério de ferro com projeto em Caetité. Salvador, 2010.

HYDROS, Engenharia e Planejamentos. Relatório de Impacto Ambiental (RIMA). Porto Sul. 2012. 118p.

DNPM - Departamento Nacional de Produção Mineral:

A importância econômica da mineração no Brasil, 2011. 24p.

Informe Mineral. Brasília, 2013 18p.

Informe Mineral. Brasília, 2014. 23p.

FAUSTINO, C.; FURTADO, F. Mineração e violação de direitos. O projeto ferro de Carajás S11D da Vale. Relatório da missão de investigação e incidência. $1^{\underline{a}}$ ed. 2013. 129p.

IBGE. Instituto Brasileiro de Geografia e Estatística. Documentação Territorial do Brasil, 2010. 4 p.

IBRAM. Instituto Brasileiro de Mineração. Indústria da Mineração, Ano V, no 37. Brasília, 2010. 16p.

MME - Ministério de Minas e Energia. Minério de Ferro. Relatório Técnico 18. Perfil da Mineração de Ferro. Desenvolvimento de Estudos para Elaboração do Plano Duodecenal (2010 2030) de Geologia, Mineração e Transformação Mineral. Projeto de Assistência Técnica ao Setor de Energia. 2009. 63p.

OIKOS, Cooperação e Desenvolvimento. Organização Não Governamental para o Desenvolvimento. Estudo de Impacto Ambiental (EIA) das obras de implantação da ferrovia oeste leste, entre Figueirópolis (TO) e Ilhéus (BA). Volume 1, 2009. 142p.

SEI - Superintendência de Estudos Econômicos e Sociais da Bahia. Anuário Estatístico da Bahia, v. 26. Salvador, 2012. $692 p$.

SEPLAN ${ }^{1}$, Secretaria de Planejamento da Bahia. Relatório de Atividades. Bahia que faz: Densificação da Base Econômica e Geração de Emprego e Renda. Governo da Bahia, 2006. 34p.

SEPLAN², Secretaria de Planejamento da Bahia. Revista Bahia Invest, Salvador, v. 4, n. 7. Governo da Bahia, 2006. 32p.

SEPLAN, Secretaria de Planejamento da Bahia. Ferrovia de Integração OesteLeste, 2010. Disponível em $<$ http://www.seplan.ba.gov.br/verProjeto. php?varCodigo $=6>$

SILVA, N.L.O. Caetité: um estudo do desenvolvimento local. Dissertação. Universidade Salvador - UNIFACS. Salvador, 2007. 326p.

STEINWEG, T; SCHUIT, A. Impactos of the global iron ore sector. Case study: Altain Khuder in Mongolia. SOMO, 2014. 39p.

USGS - United States Geological Survey. Iron Ore. Mineral Commodity Summaries. 2014. p. 84-85.

USGS - United States Geological Survey. Iron Ore. Mineral Commodity Summaries. 2015. p. 84-85.

VALEC - Engenharia, Construções e Ferrovias. Ferrovias VALEC. Ministério dos Transportes. 2013. 1p.

World Bank. Global Economic Prospects. Washington 2014. 144p. 